\title{
Fotografias de deslocamentos no Ambiente: fugas em uma prática educativa Leandro Belinaso Guimaräes ${ }^{l}$ \\ Ana Maria H. Preve ${ }^{2}$
}

\section{RESUMO \\ FOTOGRAFIAS DE DESLOCAMENTOS NO AMBIENTE: FUGAS EM UMA PRÁTICA EDUCATIVA.}

Professores olham para fotografias tiradas com câmeras pinhole, durante um percurso configurado previamente, por um parque ambiental, como uma trilha própria à educação. Nada nas fotos indica as flores, os dejetos, o lixo, o rio, os lírios e as "harmonias na natureza" apontadas pelos professores. No entanto, enquanto produzem legendas para as fotografias, na oficina que ministramos a partir delas, há certa insitência em ver o que elas não mostram. Nelas, para um estranho que não percorreu aquela trilha, não há sequer marcos que retratem o percurso feito. São outras e novas as imagens do percurso. São deslocamentos na e da paisagem - esse "lugar" em que se chocam e se ativam linhas visíveis e invisíveis. Nosso movimento de escrita ruma ao encontro de experiências em educação ambiental que tenham como princípio o enfraquecimento das imagens-clichês, a despoluição do nosso invisível e uma escrita afetada pelas forças do indizível. Palavras-chave: imagem; ambiente; educação ambiental; formação de professores.

\section{ABSTRACT \\ PHOTOGRAPHS IN THE ENVIRONMENT: LEAKS IN AN EDUCATIONAL PRACTICE.}

Teachers look at their photographs taken using pinhole cameras at an environmental Park where educational trails can be found. Nothing in the photos showed flowers, lilies, waste $r$ trees. However, they insist that these things appear in the photos. The mysterious and enigmatic pinhole photos turned into realistic images but there is a "new" Park in them. From the cultural studies perspective, the article describes this experience on how the cliches affect us and how it is possible to see the invisible lines in an environment or in a photo. Key words: image; environment; environmental education; teachers training.

\footnotetext{
1 professor adjunto do Departamento de Metodologia do Ensino (MEN) do Centro das Ciências da Educação (CED), da Universidade Federal de Santa Catarina (UFSC). Na mesma Universidade, atua no Programa de Pós-Graduação em Educação (PPGE), na linha Educação e Comunicação, desenvolvendo e orientando pesquisas de mestrado e de doutorado articuladoras da educação (e da educação ambiental) com os estudos culturais.

2 Professora no Curso de Geografia da Universidade do Estado de Santa Catarina (UDESC). Desde o mestrado, vêm atuando em Educação, com ênfase na Formação de Professores e na prática de pesquisa com oficinas. Desenvolve pesquisa em educação, geografias e imagens e dessa atuação (no ensino, na pesquisa e na extensão) os trabalhos desdobram-se em temas como educação e meio ambiente, educação em geografia, educação em espaços não-formais.
}

Ci. Huma. e Soc. em Rev. RJ, EDUR, vol. 35, n. 2, jul / dez, p. 48-59, 2013 


\section{INTRODUÇÃO}

“O invisível [...] é também sempre um pouco indizível, e já terei conseguido muito se puder roçá-lo de leve para indicar a relação fundamental que creio haver entre ele e uma reflexão sobre as ecologias." Peter Pál Pelbart. A nau do tempo rei.

Este trabalho é decorrente dos estudos e das pesquisas que nós autores vimos desenvolvendo, nos últimos anos, sobre as relações entre imagem, educação e ambiente. Em pesquisas distintas, levadas a cabo por cada um de nós, temos nos dedicado a conversar com as imagens sobre o ambiente produzidas e/ou consumidas em nossas práticas profissionais [atuamos na formação de professores] e/ou vivências cotidianas. Em algumas dessas imagens, enxergamos muitos dos clichês recorrentes na cena cultural [e sobre eles também têm nos interessado conversar], e em outras, intuímos a potência de outros modos de pensar o ambiente e as nossas relaçóes socioambientais.

Algumas vezes, como no caso das imagens com as quais conversaremos neste texto, uma imagem pode potencializar um pensamento outro sobre o ambiente e, ao mesmo tempo, reforçar um clichê. Interessante paradoxo. Como seria possível uma mesma imagem incitar modos distintos de ver? Ou será que são os focos diferenciais que lançamos a uma imagem, focos carregados de nossas experiências, de nossos repertórios culturais, de nossas aprendizagens cotidianas, que nos remetem à leituras tão díspares umas das outras sobre uma mesma imagem? Certamente, como sugere Stuart Hall (1997), nós compartilhamos, coletivamente, significados sobre o mundo. Há representações recorrentes e modos comuns de ver. Sem uma ampla e vertiginosa circularidade pela cultura, os clichês dificilmente teriam tanta força sobre nossas "almas".

Como diz Bernardina Leal (2009, p. 151), “da paisagem que vemos, já não podemos nos retirar”. Assim, nos modos como lemos uma imagem, há um pouco daquilo que pensamos ser. Transgredilas, ou seja, pensá-las para além daquilo que uma "ecologia maior"3 já nos acostumou a ver é, nesse sentido, um ato de deslocamento de si, dos nossos modos costumeiros de ver. Como pode uma imagem silenciosa, aberta, imaginativa, inventiva,

desfocada [tais como as que estaremos dispondo neste trabalho] servir, também, para o reforço de um (ou mais) clichês? Talvez nossas práticas pedagógicas necessitem exercitar deslocamentos não apenas da imagem em si mesma, mas também dos nossos focos.

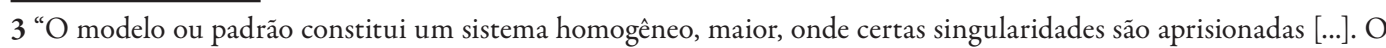
modelo ou padrão majoritário diz respeito a tudo aquilo que é traduzível, transmissível, comparável, racional e útil para o homem por meio de um planejamento da vida”. (GODOY, 2008, p. 58) Para saber mais sobre como o conceito de menor afirma uma potência, sugerimos a leitura do livro aqui citado. 
Neste trabalho, socializamos esse entendimento pedagógico apreendido através das nossas pesquisas: uma prática pedagógica em educação ambiental, para ter um efeito no cotidiano de nossas vidas, tal como afirma Marcos Reigota (2008), necessita provocar deslocamentos nos modos de pensar e de ver. Para tanto, consideramos as imagens como artefatos férteis para as práticas pedagógicas nas quais nos envolvemos e, em razão disso, investigá-las têm sido muito instigante.

Esse desejo comum de pensar as relações entre imagem, educação e ambiente, aliado ao entrelaçamento das nossas referências teóricas e práticas, advindas dos estudos culturais e da filosofia da diferença, nos permitiu potencializar um encontro. Através dele nos vimos (os autores deste trabalho - professores de universidades públicas distintas), juntos, como docentes frente a um grupo de professores e de professoras da educação básica de diferentes áreas do conhecimento escolar. Com eles, exercitamos um pouco o que nossas investigações sobre imagem e ambiente vinham nos dizendo e ainda conquistamos mais elementos para aprofundar nossas reflexões.

Neste texto, primeiramente falamos sobre a pedagogia que inventamos para que imagens pudessem se criar. E mais, queríamos que elas permitissem potencializar conversas instigantes sobre o ambiente. Nessa seção inaugural do trabalho, apontamos alguns entendimentos sobre a relação entre imagem, ambiente e educação que nos interessa discutir. Mais adiante, na segunda e última seção, apresentamos quatro fotos tiradas por professores durante uma oficina de formação continuada, bem como pequenas narrativas elaboradas sobre elas, em forma de legenda, pelos professores. A partir das imagens e de suas legendas, apresentamos uma breve discussão atentando, sobretudo, às representações do ambiente, aos modos de leitura das imagens e à sua potência educativa.

\section{A produção das imagens: pedagogias inventivas}

Trabalhamos por um dia inteiro com cerca de trinta professores interessados em educação ambiental, na possibilidade de pensar suas práticas pedagógicas nas escolas e em outros espaços sociais. Em uma oficina anterior à nossa [mas inserida no mesmo curso de formação continuada], os professores haviam confeccionado câmeras fotográficas pinhole $e^{4}$ a partir de pequenas caixas de suco vazias. De posse dessa ferramenta, fizeram uma trilha em um parque destinado à proteção ambiental. A ordem era para que esses professores tirassem fotografias daquilo que desejassem durante o percurso.

\footnotetext{
4 "Esta é uma técnica fotográfica pela qual uma imagem pode ser obtida pela introdução de um material fotossensível dentro de um compartimento fechado, em que a entrada de luz se dá apenas por um pequeno orifício, táo pequeno que normalmente é feito com agulha ou alfinete (por isso o nome proveniente do inglês, pin: alfinete e hole: buraco). Fotografar pelo buraco ou furo de agulha é, assim, criar uma câmara escura, deixar a luz entrar e fixar uma imagem no filme ou papel fotográfico, sem o intermédio de lentes, as chamadas objetivas." (FAVERO, 2012) 
Na trilha, inspirados pelo trabalho de Janice Zanco $(2010)^{5}$, foram propostas situações diferenciadas que causassem certos estranhamentos no percurso, visando a provocar olhares incomuns para uma trilha educativa realizada num parque - já tão repleta de certas expectativas: aprender sobre o parque, sua ecologia, sua fauna, sua flora (SAMPAIO; GUIMARÃES, 2009).

Percorrer trilhas, definidas anteriormente por especialistas, quer dizer prestar atenção ao que um dia foi assinalado por alguém como importante para explicar um fato, um animal, uma planta, uma particularidade de um ecossistema, uma história, uma rocha, um processo geográfico, biológico, ecológico qualquer. Tal como coloca Marco Pólo a Kublaikhan, ao falar sobre a cidade de Tamara, "penetra-se por ruas cheias de placas que pendem das paredes. Os olhos não vêem coisas, mas figuras de coisas que significam outras coisas: o torquês indica a casa do tira-dentes; o jarro, a taberna; as alabardas, o corpo de guarda...”. (CALVINO, 1990, p. 17) Há, na trilha, outros símbolos advertindo situações proibidas: não jogue lixo no chão; não retire nada do ambiente; não faça barulho; não pise fora da trilha etc.

Assim, o olhar de quem as percorre segue placas, procura nelas o que pode e deve ser visto. Neste caso, propusemos algo diferenciado. Cobrimos todas as placas explicativas ao longo do caminho com sacos pretos para que o olho, sem o auxílio delas, pudesse percorrer o parque em busca de algo diferente, encontrando novos focos de observação. Também não havia um guia direcionando olhares e capturando atenções. Os participantes usavam antenas coloridas (dessas que adornam fantasias de festas de crianças, compradas em lojas de $\mathrm{R} \$ 1,99)$ e foram aconselhados a não tirálas para que ativassem a possibilidade de captar com maior sensibilidade os detalhes (sons, ruídos, vibrações, cheiros, tonalidades de cores, texturas, espessuras...) não disponíveis aos viciados olhos, narizes, ouvidos, corpos já acostumados a percorrer uma trilha num parque ou em outra área ambiental. Ao longo da trilha, foram dispostos sons: em um ponto havia um barulho típico de uma cena urbana; em outro, cantos de pássaros. Objetos foram alocados ao longo do caminho: um pé de sapato feminino de festa, um computador portátil. De repente, em sentido contrário ao que caminhavam os professores, um sujeito de terno e gravata, personificando um executivo, seguia rapidamente pela trilha. Foi nesse cenário, com uma câmara pinhole em mãos - confeccionada por cada um dos professores -, no interior dessa inusitada trilha, que as imagens a serem apresentadas na próxima seção foram produzidas.

5 O trabalho desta pesquisadora envolveu criar estratégias de escuta para que o parque ambiental estudado fosse visto por crianças, moradoras de suas proximidades, a partir das narrativas de outras vozes pouco comuns nas trilhas interpretativas de educação ambiental. 
As câmeras pinhole, por si mesmas, possibilitam-nos outras imagens, muito diversas daquelas com as quais estamos acostumados quando usamos uma máquina digital ou mesmo uma analógica. Nossa proposta foi, exatamente, pensar com os professores e com as professoras sobre as imagens produzidas na trilha. Queríamos sair da noção de que a foto serve apenas para ilustrar, representar o que foi visto, queríamos fotos novas, queríamos outros ambientes, percursos, poesias. Precisávamos de uma ferramenta que interferisse na informação sobre aquele espaço. Queríamos ver, no mesmo lugar, paisagens mais poéticas ou, ainda, abrir possibilidades nas paisagens visíveis para vermos aquilo que, pelo excesso de informação, já não temos como enxergar. Portanto, as interferências produzidas naquele meio - "naquelas ruas cheias de placas" (CALVINO, 1990) - ao cobrirmos as placas com sacos plásticos pretos e inserirmos elementos nada comuns àquela trilha, provocaram $\mathrm{e}$ ativaram uma outra atenção corporal, uma espécie de atenção ativa nos encontros inesperados que aquele percurso podia trazer; uma atenção que punha o corpo todo em movimento no percurso, capaz de produzir algo novo no que estava acontecendo. Os pontos fixados nas fotografias tiradas eram o modo como a atenção de cada um se configurava. Destaca-se, então, que às imagens que nos chegaram após a revelação das fotografias, não era mais possível perguntar: "o que é isto?" No entanto, frente às nossas impossibilidades, tal pergunta imperou, tornando-se insistente.

Nesse jogo entre o que está dado para ser visto, as representações que temos e aquilo que escapa à visão, o termo ecologia do invisivel é um dos que anima o presente trabalho. Sua importância reside no esforço que vimos desenhando em nossas pesquisas para abarcar determinada porção de mundo submetida ao efeito dos clichês. Em meio a este mundo, no qual abunda o excesso de informação e de clichês, as forças fugidias, inventivas, intensivas, imaginativas, tornam-se algo de difícil captura, de difícil encontro. Com este trabalho, tratamos de captar as forças de um ambiente e torná-las, a partir de outros meios, visíveis. As câmeras pinhole foram usadas como ferramentas de captura de tais forças e não das formas representativas que se distribuem por determinado ambiente. Um percurso, uma trilha, um caminho, uma curta distância extensiva qualquer é, ao mesmo tempo, a reunião de componentes visíveis e invisíveis. Lembrando que o invisivel é também um pouco indizivel...

Nessa linha, ante a quase impossibilidade de dizer do invisível, desenhamos um caminho para abordar a questão das imagens no/do ambiente na formação de professores de modo a subverter a relação direta entre fotografia e/ou qualquer outra imagem e a sua tradução da realidade.

A questão que nos acompanha nestes trabalhos com professores e professoras coloca-se no sentido de alargar visões de mundo, nossas visões. Por isso, inventamos ferramentas que possibilitam uma outra relação com o invisível que todo meio comporta, "como se esse invisível fosse essa camada que envolve e permeia as coisas, ou que as duplica, ou que lhes dá espessura...” (PELBART, 1993, p. 53). 
E como segue argumentando o autor:

Uma ecologia que pretendesse preservar o ar relativamente despoluído, isto é, invisível, deveria preocupar-se em manter arejado o invisível. Pois se o regime da visibilidade total é incapazdesubstituiroinvisível,eleébemcapazdeopoluir.Oqueexperimentamosnumnível mais imediato, apesar de todas as possibilidades alentadoras que as tecnologias inventam sem cessar,éjustamente isso: uma espécie de poluição do invisível.(PELBART, 1993,p. 54)

O objetivo do trabalho com os professores era viajar através dessas outras imagens do ambiente. Em um primeiro momento, distribuímos as imagens extraídas do percurso (reveladas e ampliadas) para cada um dos professores. Depois, em duplas, eles teriam que selecionar de comum acordo somente uma imagem dentre as que dispunham. Feita a escolha e a composição do argumento para essa seleção, solicitamos que uma legenda fosse produzida para a imagem selecionada. Em seguida, as duplas trocaram as fotos e outra dupla legendou pela segunda vez a imagem, sem saber qual era a legenda anterior. No final do exercício tínhamos algumas imagens (mais ou menos quinze), sendo que cada uma trazia duas legendas. Esse era o material do qual dispúnhamos para começar a conversa com os professores. Para este texto, selecionamos quatro imagens, que serão apresentadas a seguir, acompanhadas de suas legendas, a partir das quais desenvolveremos alguns aspectos de nossos achados de pesquisa.

Sugerimos que os leitores e as leitoras leiam silenciosamente as imagens e, somente depois, as legendas. Façam o exercício de pensar sobre a seguinte questão: o que a imagem me evoca, me remete a pensar? E mais: que ambiente ela inventa? Em que ambiente me vejo hibridado ao ler a imagem? O que está acontecendo na foto? Remeto minha leitura a uma representação de ambiente que já carrego em mim, buscando nela alguma "realidade" de antemão conhecida? Permito-me imaginar um ambiente outro, não conservado nas representações mais recorrentes? Voltamos a insistir numa atenção ativa no encontro de cada um com essas fotos, sem se perguntar "o que é isso?", e sim “o que está acontecendo ali?” porque o que está em jogo, tal qual no percurso, é antes “acompanhar um processo e não representar um objeto”. (KASTRUP, 2009, p. 45) 


\section{Invenções” ou “o que está acontecendo?”}

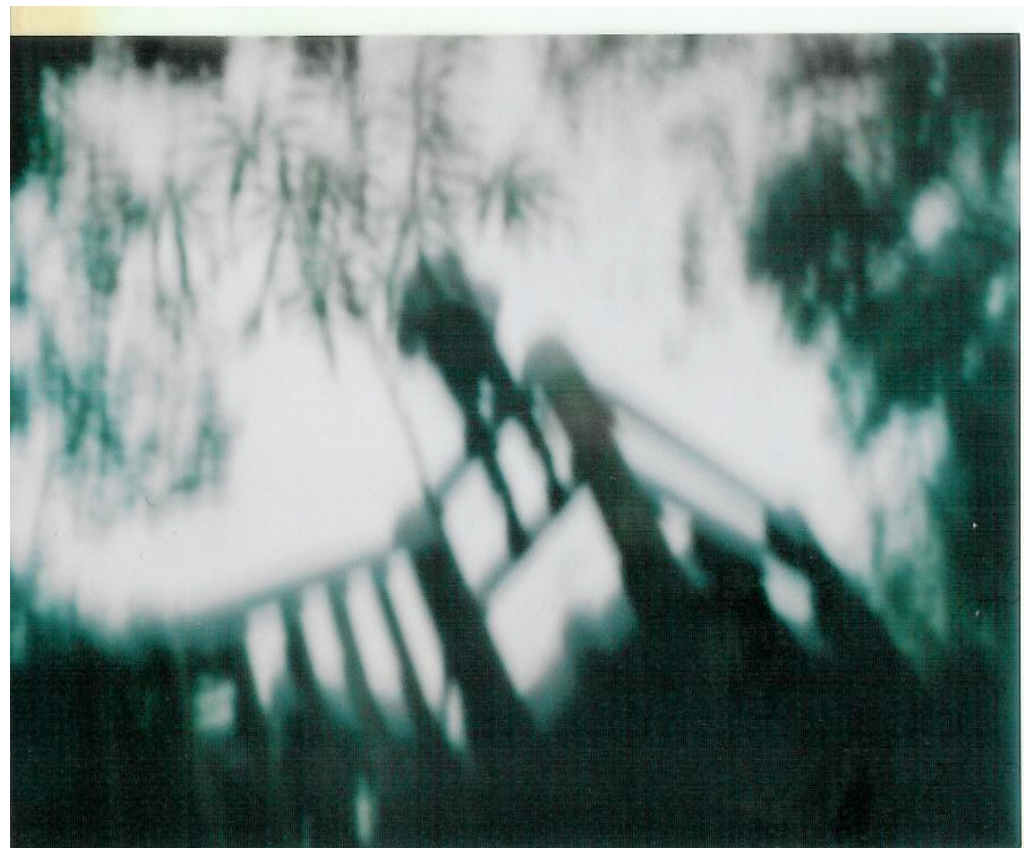

Legenda A1: "A caminho da luz"

Legenda A2: "O suicídio"

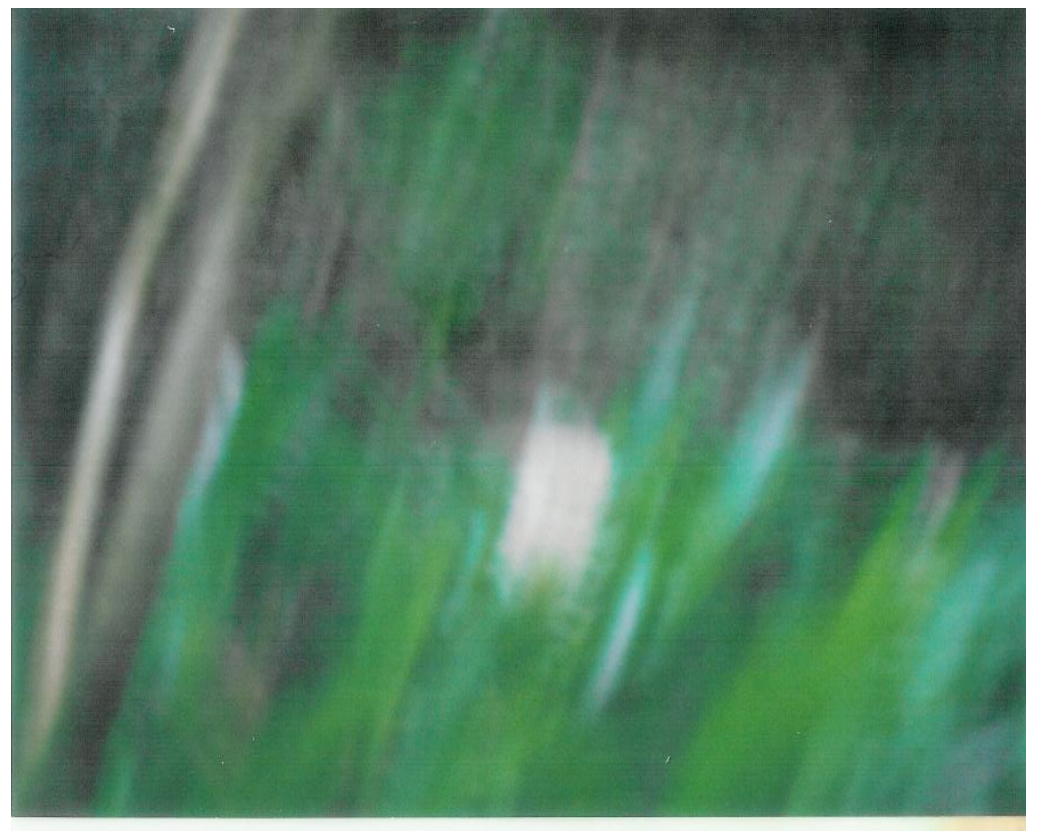

Legenda B1: "Lírio"

Legenda B2: "A harmonia da natureza" 


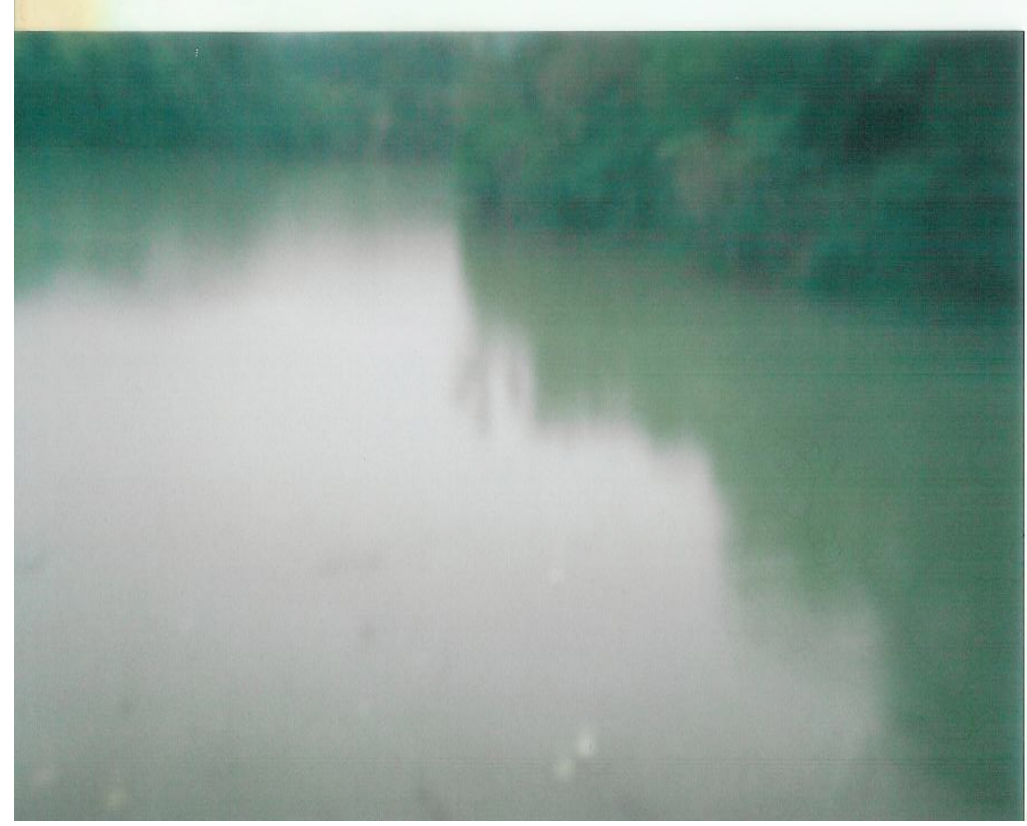

Legenda C1: "No meio do paraíso... o lixo" Legenda C2: "Experiências que interferem na paisagem"

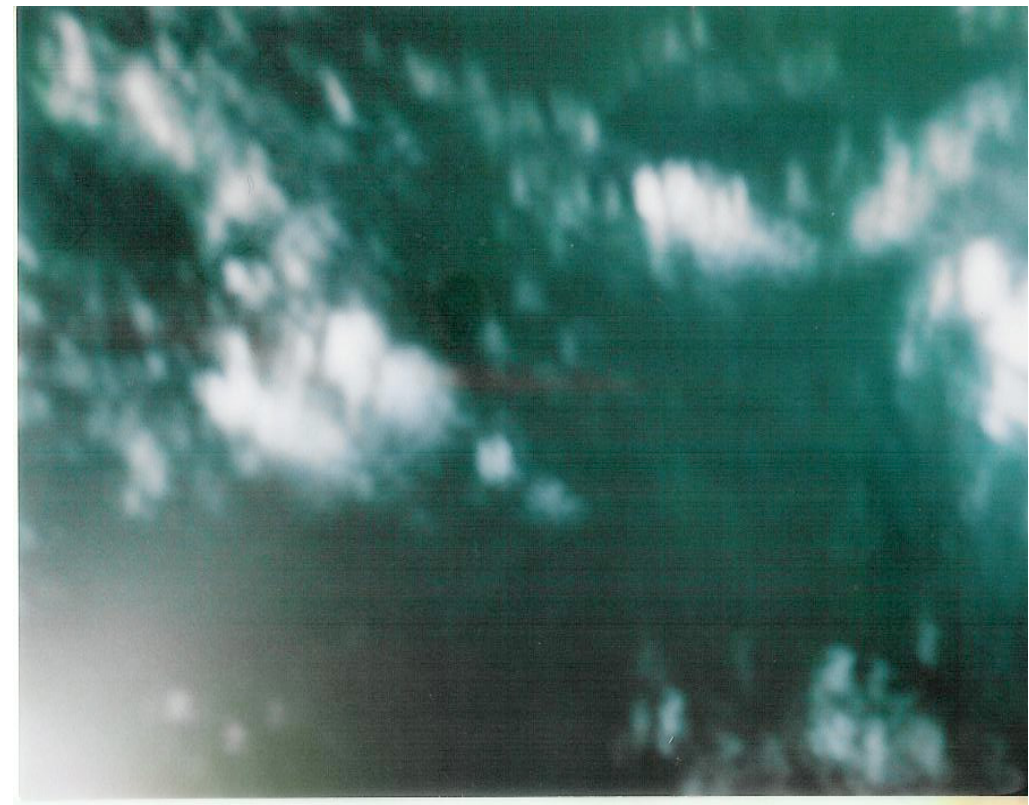

Legenda D1: "Lírio do brejo" Legenda D2: "Flores" 
Ao depararem-se com as imagens reveladas e ampliadas, o grupo foi tomado por um susto. Suas imagens não correspondiam com as formas fotografadas. Fotos distorcidas, tremidas, estouradas, escuras, manchadas eram, então, inúteis para dar conta do percurso realizado no parque. A tentativa de dizer o que estaria na imagem se processou pelas legendas e pelos comentários feitos sobre as fotos: "ali estão as flores", "aqui é um lírio", "isso é lixo no meio do rio”, "aqui é um homem fotografando a paisagem", e, novamente, "isso é o lírio do brejo". Mas, ao mesmo tempo, se olhássemos apenas para as imagens tiradas, nada do que o grupo de professores expressava através dos comentários estava acontecendo nas imagens. Nelas, havia toda uma potência para despertar a atenção para os elementos invisíveis do lugar. O parque, possibilitado por essas imagens, apresentava-se como um lugar até então não visto: horizontes novos, margens, cantos, rastros, luzes, sombras, vidas estranhas... Era inútil querer uma flor na imagem, um lírio. Mas essas legendas e esses comentários respondiam à insistente pergunta: “o que é isto?” Para nós, era exatamente essa inutilidade que abria espaço para um pensamento outro, para um parque outro, para um detalhe diferencial, invisível, do ambiente. Enfim, abria às invenções pela via da atenção ao presente das fotografias, ao que elas nos remetiam por elas mesmas e não por lembrança do que se quis delas.

Houve, em geral, certa resistência para uma viagem inusitada, para olhar o que estava silenciosamente diante dos olhos. É como se os professores tivessem sido capturados por uma informação ambiental, na qual a única resposta para as imagens seriam as advindas das disciplinas escolares e/ou do que deve ser visto em uma trilha de educação ambiental. Um tipo de informação válida, autorizada, que se afasta de um aprender pelos saberes de experiências corporais ${ }^{6}$. O excesso de informação é, conforme Larrosa (2001), parte da impossibilidade da experiência no presente. Informados, nos mantemos tranquilos, repetindo slogans apenas. Segundo Godoy (2008), nos percursos interessam as conexões, os elementos que cada um vai juntando, dando sentido etc. $\mathrm{O}$ que interessa mesmo é, ainda, "mobilizar o corpo, o pensamento, sensibilizá-los de modo que cada um experimente a paisagem, faça conexões, traçando linhas e acompanhando-as, linhas por meio das quais a paisagem se desmancha e se inventa”. (GODOY, 2008, p. 135) Experimentar é de algum modo uma oportunidade de avariar, de decompor, de desmanchar a linha da informação sobre os elementos que compõem as paisagens, o modo como eles se distribuem e desejam ser vistos.

Como é realmente Tamara? - ou ainda aquela trilha "sob esse carregado invólucro de símbolos" (CALVINO, 1990, p. 18) que determinam o olhar, impedem o corpo de experimentar. O que ela contém e o que ela esconde?

\footnotetext{
6Saberes de experiências corporais relacionam-se, segundo Oliveira Jr. (2003, p. 38), “às experiências espaciais cotidianas, entendendo esse corporal como indicativo de algo encarnado, intenso, de modo a diferenciar essas experiências corporais de 'vivências' superficiais e fugidias". O autor apoia-se na ideia de vivência e experiência apresentada por Walter Benjamin no texto "O narrador" e também na noção de experiência apresentada por Jorge Larrosa (2002) no texto "Notas sobre a experiência e o saber de experiência”.
} 
Nossas questões no trabalho com educação, imagem e ambiente rumam ao encontro (e na promoção) de experiências em educação ambiental que tenham como princípio experimentar a paisagem e, nesse sentido, rumam também para a despoluição do nosso invisível "não num sentido asséptico de preservação, mas de possibilitação." (PELBART, 1993, p. 54)

O que experimentamos cotidianamente, em um nível mais imediato, nas escolas, nas ruas, nos programas televisivos, nos filmes, nas relações humanas, nas nossas relações com as imagens e com as palavras é, na maioria das vezes, uma poluição do invisivel. Cercados que estamos por uma quantidade demente de imagens e palavras, de informação, tal cerceamento forma um mundo "na medida da disponibilidade da informação. Não seria esse o mundo que a Educação Ambiental, concorrendo com tantos outros dispositivos, está produzindo?” (PREVE; CORREA, 2007, p. 219).

Um pintor nunca fica diante de uma superfície em branco. Se estivesse poderia reproduzir nela qualquer objeto exterior. Como diz Deleuze (2007):

O pintor tem várias coisas na cabeça, ao seu redor ou no ateliê. Ora, tudo o que ele tem na cabeça ou ao seu redor já está na tela, mais ou menos virtualmente, mais ou menos atualmente, antes que ele comece o trabalho. [...] De tal forma, diz ele, que o pintor não tem que preencher uma superfície em branco, mas sim esvaziá-la, desobstruí-la, limpá-la. [...] Em suma, o que é preciso definir são todos esses dados que estão na tela antes que o trabalho do pintor comece.(DELEUZE, 2007, p. 91)

Antes que nosso trabalho em educação ambiental comece, precisamos saber quais os clichês que estão ativos, precisamos entrar neles. Nãoéfugir dos clichês, mas antes perceber “entre esses dados, quais são um obstáculo, quais são uma ajuda" (DELEUZE, 2007, p. 91) para um novo trabalho em educação ambiental. Não se escapa dos clichês sem antes entrar neles. Mergulhar na imagem poderia ser uma aventura. Quem sabe exigiria, sabendo dos clichês que operam em nós, esquecer agora, um pouco, o parque, o lugar de onde elas brotaram. As imagens que você, leitor e leitora viram, parecem ter voado e chegado de um outro lugar que não o que habitamos ou percorremos. Talvez não tenhamos estado no lugar de onde as imagens vieram, pois se trata de um lugar a ser criado agora pelas imagens que nos chegaram. Que mundos se abririam nesse exercício inventivo de leitura? Como sonharíamos o ambiente? Que outras legendas/narrativas se criariam? Inventamos com isso um modo, uma técnica para extrair dos clichês algo que possa servisto e, por extensão, dito. Uma técnica para ver as paisagens.

Desejamos que você, leitor e leitora, possa também imaginar com as imagens presentes nesse trabalho ambientes outros, que possa pensar seus focos para o mundo e, quem sabe, vislumbrar outras relações socioambientaisaonãoseguirenfocandotudoaquiloquejáestá,desdeantesesempre,nospreenchendo. 
Terminamos com Calvino. No trecho citado anteriormente ele diz que percorremos as ruas de uma cidade como se fossem páginas escritas: ela nos diz tudo o que devemos pensar, e nós, informados, repetimos o discurso. Quando acreditamos estar visitando, estamos...

Do lado de fora, a terra estende-se vazia até o horizonte, abre-se o céu onde correm as nuvens. Nas formas que o acaso e o vento dão as nuvens, o homem se propõe a reconhecer figuras: veleiro, mão, elefante... (CALVINO, 1990, p. 18)

\section{REFERÊNCIAS:}

CALVINO, Ítalo. As cidades invisíveis. Tradução Diogo Mainardi. São Paulo: Companhia das Letras, 1990.

DELEUZE, Gilles. Francis Bacon: lógica da sensação. Coordenação da tradução Roberto Machado. Rio de Janeiro: Jorge Zahar, 2007.

FAVERO, Franciele. Fugas por entre furos de agulhas. In: PREVE, Ana Maria Hoepers, GUIMARÃES, Leandro Belinaso, BARCELOS, Valdo, LOCATELLI, Julia (Orgs). Ecologias Inventivas: conversas sobre educação. Santa Cruz do Sul: EDUNISC, 2012.

GODOY, Ana. A menor das ecologias. São Paulo: EDUSP, 2008.

HALL, Stuart. A centralidade da cultura: notas sobre as revoluções culturais do nosso tempo. Educação e Realidade, Porto Alegre, n. 22, v. 22, p. 15-46, jul./dez. 1997.

KASTRUP, Virginia. O funcionamento da atenção no trabalho do cartógrafo. In: PASSOS, Eduardo, KASTRUP, Virginia, ESCÓSSIA, Liliana da. Pistas do método da cartografia: pesquisa-intervenção e produção de subjetividade. Porto Alegre: Sulina, 2009.

LARROSA, Jorge. Notas sobre a experiência e o saber de experiência. Tradução de João Wanderley Geraldi. Revista Brasileira de Educação, n. 19, jan./abr. 2002. Disponível em: <http://educa.fcc. org.br/pdf/rbedu/n19/n19a03.pdf> Acesso em: 2.03.2012.

LEAL, Bernardina. Janela. In: KOHAN, Walter Omar; XAVIER, Ingrid (Orgs). Abecedário de criação filosófica. Belo Horizonte: Autêntica, 2009.

OLIVEIRA JUNIOR, Wenceslao Machado. Aproximações entre a Educação, as Fotografias e as Geografias do lugar onde se vive: um estudo a partir do Atlas Municipal Escolar de Rio Claro. In: 7 Encontro Nacional de Prática de Ensino de Geografia, 2003, Vitória. Anais do 7 Encontro Nacional de Prática de Ensino de Geografia. Vitória, 2003.

PELBART, Peter Pál. A nau do tempo rei: sete ensaios sobre o tempo e a loucura. Rio de Janeiro: Imago, 1993. 
PREVE, Ana Maria, CORRÊA, Guilherme. Ecologia de Rebanho. In Ambientes da Ecologia: perspectivas em política e educação. Santa Maria: Ed. Da UFSM, 2007.

REIGOTA, Marcos; PRADO, Bárbara Heliodora Soares do (Orgs). Educação ambiental: utopia e práxis. São Paulo: Cortez, 2008.

SAMPAIO, Shaula, GUIMARÃES, Leandro Belinaso. Educação Ambiental: tecendo trilhas, escriturando territórios. Educação em Revista, Belo Horizonte: FAE/UFMG, n. 3, vol. 25, dez. 2009.

ZANCO, Janice. Dona Generosa e as crianças disparam... outros modos de ver a Lagoa do Peri. 2010, 117p. Dissertação (Mestrado em Educação) - Centro de Ciências da Educação, Programa de Pós-Graduação em Educação, Universidade Federal de Santa Catarina, Florianópolis, 2010. 